\title{
Corrigendum
}

\section{Corrigendum to "3D-Printed Graphene Antennas and Interconnections for Textile RFID Tags: Fabrication and Reliability towards Humidity"}

\author{
Han He $(\mathbb{D}$, Mitra Akbari $(\mathbb{D}$, Lauri Sydänheimo, Leena Ukkonen $(\mathbb{D}$, and Johanna Virkki \\ BioMediTech Institute and Faculty of Biomedical Sciences and Engineering, Tampere University of Technology, P.O. Box 692, \\ 33101 Tampere, Finland \\ Correspondence should be addressed to Han He; han.he@tut.fi \\ Received 22 July 2020; Accepted 23 July 2020; Published 26 September 2020 \\ Copyright $\odot 2020 \mathrm{Han} \mathrm{He}$ et al. This is an open access article distributed under the Creative Commons Attribution License, which \\ permits unrestricted use, distribution, and reproduction in any medium, provided the original work is properly cited.
}

In the article titled "3D-Printed Graphene Antennas and Interconnections for Textile RFID Tags: Fabrication and Reliability towards Humidity" [1], the Acknowledgments section should be corrected as follows:

"This research work was supported by the Jane and Aatos Erkko Foundation, Academy of Finland (decision number 294534) and TEKES."

\section{References}

[1] H. He, M. Akbari, L. Sydänheimo, L. Ukkonen, and J. Virkki, "3D-printed graphene antennas and interconnections for textile RFID tags: fabrication and reliability towards humidity," International Journal of Antennas and Propagation, vol. 2017, Article ID 1386017, 5 pages, 2017. 